\title{
A spatial economics perspective on convergence research of carbon emissions performance in China
}

\author{
Jianzhou $\mathrm{Tu}^{1}$, Dalai $\mathrm{Ma}^{2 *}$ \\ ${ }^{1}$ School of Economics and Business Administration, Chongqing University, Chongqing 400044, China \\ ${ }^{2}$ School of Management, Chongqing University of Technology, Chongqing 400054, China
}

Corresponding Author Email: madalai@163.com

https://doi.org/10.18280/ijht.360324

Received: 18 March 2018

Accepted: 1 July 2018

\section{Keywords:}

carbon emissions performance, convergence, spatial economics, China

\begin{abstract}
With the goal of expeditiously attaining strong efficiency in energy use, this paper constructs a function of carbon emissions performance to measure the carbon emissions performance on a provincial level from 1998 to 2016 in China. With panel data from 30 provinces, a spatial panel data model is established to test the convergence on carbon emissions performance in China. The results showed that the average carbon emissions performance in eastern coastal provinces was clearly higher than that of inland provinces during the sample period. Seen by regions, there was a steady upward trend of carbon emissions performance in eastern, central, and western China, while carbon emissions performance in eastern China was higher than that in central and western China. According to Moran's I indexes, there is a strong spatial correlation and obvious cluster tendency in regional carbon emissions performance. LISA shows that spatial dependence of carbon emissions performance exists in most provinces in China, but the spatial difference exists in only a few provinces. The addition of spatial effect revealed that there were both absolute $\beta$ convergence and conditional $\beta$ convergence in regional carbon emissions performance from 1998 to 2016. Convergence of carbon emissions performance is significantly influenced by factors such as economic scale, industrial structure, governmental intervention, energy structure, and technological advancements. The influence of FDI on carbon emissions performance was insignificant.
\end{abstract}

\section{INTRODUCTION}

Currently, the rapidly growing domestic economy has not only contributed to a great rise in wealth, but has also produced large amounts of carbon dioxide emissions. Statistical data from CDIAC showed that the amount of carbon dioxide emissions in China was 1.5 billion tons in 1980 . This amount has drastically risen to 6.8 billion in 2008, an increase of 4.53 times in three decades with an annual increase rate of over $5.54 \%$. However, the extensive pattern of domestic economic growth in China is accompanied by a great increase in production. Such economic growth is based on high levels of investment, energy consumption and emissions, and has greatly hindered emissions reduction efforts.

At the climate conference in Copenhagen in 2009, China announced its promise to reduce the amount of carbon dioxide emissions per GDP in China by $40 \%-45 \%$ in 2020 , which puts great pressure on China to live up to its commitment. Thus, it is essential for China to implement energy conservation plans and reduce the amount of carbon dioxide emissions by improving carbon emissions performance; i.e., lowering emissions while maintaining the same level of production. However, in reality, there are great regional differences in carbon emissions performance in China and great differences among provinces in resources endowment. Thus, it is of great importance to improve provincial carbon emissions performance and to discuss the internal influencing mechanism in terms of narrowing the gap in regional carbon dioxide emission efficiency in the field of energy conservation and emissions reduction in China.

\section{LITERATURE REVIEW}

The issue of carbon dioxide emission performance is of great interest in the academic field. Globally, both consensus and divergence coexist in aspects such as measurement indexes, computation methods, and convergence. First, conceptually, carbon dioxide emission efficiency can be divided into the single-factor type and the total-factor type. The typical single-factor carbon dioxide emission efficiency has various definitions, such as the amount of $\mathrm{CO}_{2}$ emission per unit GDP [1-2], the carbon dioxide emission per unit energy consumption [3], and the carbon dioxide production rate [4]. The total-factor carbon dioxide emission efficiency also refers to the comprehensive carbon dioxide emission efficiency [5-6] or the total-factor efficiency of carbon dioxide emission [7]. The measurement index of the single-factor carbon dioxide emission efficiency is simple and easy to operate, but it is also weak in the economic sense, as it merely reflects the relationship between $\mathrm{CO}_{2}$ emission and economic growth, or unilaterally reflects the amount of $\mathrm{CO}_{2}$ emission in terms of energy consumption. However, it fails to incorporate economy, energy and environment into an integrated and unified framework of research, as well as failing to comprehensively reflect the basic technological efficiency of various input factors in the process of production. Given this, the total-factor $\mathrm{CO}_{2}$ emission performance is chosen as the objective of this paper. Meanwhile, to further expound the core concepts herein, the paper refers to relative research and defines the carbon dioxide emission performance as the 
accessible maximum economic output with minimum $\mathrm{CO}_{2}$ emission without extra capital, labor force or energy input.

Carbon dioxide emission performance of various regions should first be accurately measured before conducting the research on the convergence of regional $\mathrm{CO}_{2}$ emission efficiency. Currently, there are two measurements of $\mathrm{CO}_{2}$ emission performance [8]. One is the nonparametric method, such as data envelopment analysis (DEA), which is applied in measuring carbon dioxide emission efficiency globally by Zhou et al. [9], Zaim and Taskin [10], Zofio and Prieto [11], Marklund and Samakovlis [12], Wei et al [13]. The other is the parametric method, including Stochastic Frontier Approach (SFA), which is utilized to perform empirical analysis on carbon dioxide emission efficiency by Risto et al. [14], Zhao et al [15]. Compared to SFA, the flexible DEA does not need function by establishing an efficiency model. Meanwhile, it is appropriate for the units of data in DEA to differ from each other. Data in DEA can even be free from measurement of productivity efficiency. It is possible for externalities of environments to be set as an output in DEA. As SFA lacks the above advantages, most scholars globally adopt DFA to measure carbon dioxide emission performance.

With regard to researches on the convergence of carbon dioxide emission efficiency, researches outside China are centered on the field of the convergence of carbon dioxide emissions, while researches inside China are centered on the field of convergence of carbon emissions performance. For researches on the convergence of carbon dioxide emissions, there are two main aspects for generalization. One aspect is that most scholars establish the panel data model of various countries to conduct on-site investigations into whether there are phenomena of absolute $\beta$ convergence and conditional $\beta$ convergence in these countries [16-19]. The other aspect is that by establishing the model of club convergence based on the level of development of countries or the levels of state revenue, some scholars have worked empirically to study whether there is club convergence of national carbon dioxide emission in different clubs [20-21]. Compared with scholars outside China, Chinese scholars are more inclined to probe into the convergence of carbon dioxide emission efficiency. Representatively, based on provincial panel data, scholars such as Zhou and Nie [22], Wang et al. [23], Du and Wang [24] adopted the method of DEA to measure carbon dioxide emission efficiency in various provinces, and established the convergence model on this basis to investigate the issue of convergence in different regions.

All in all, it can be seen that scholars outside China weigh the feature of absolute amount of carbon dioxide emissions convergence, while Chinese scholars pay more attention to the economic sense of carbon dioxide emissions convergence. However, in existing researches, scholars all over $\mathrm{e}=$ the world fail to take space factors into consideration, which means that the regions to be studied are regarded as interdependent However, in reality, as the main component of greenhouse gas, carbon dioxide exhibits strong mobility, meaning that carbon dioxide emitted in one region will impact the content of carbon dioxide in other regions, namely the spatial spillover effect. Generally, carbon dioxide emission is regarded as an environmental issue by governments to be inspected from the national perspective. According to Tobler's First Law of Geography, the nearer things are, the more related they are to each other; and vice versa. Therefore, when studying the convergence of carbon dioxide emission efficiency, it is necessary to consider the issue of spatial effect among various regions [25].

There are two differences between the research herein and existing research projects on this issue. First, with regard to the research method, the method of minimum distance to the strong efficiency frontier is adopted herein as the measurement on carbon dioxide emission efficiency, which is conducive to improving the economic sense of measuring carbon emissions performance. Next, from the perspective of spatial economy, this paper establishes a spatial panel data model to inspect carbon emissions performance, and thus the precision of the assessment results of the model can be improved.

\section{RESEARCH METHODS}

\subsection{Measurement of carbon dioxide emission performance}

\subsubsection{Minimum distance to the strong efficiency frontier}

Referring to research achievements from Jahanshahloo et al. and Aparicio et al. [26-27], this paper proposes the method of minimum distance to the strong efficiency frontier. Through minimizing the distance of $\mathrm{L}_{1}$, the projective point of production frontier for the measurement of efficiency can be dertermined. Based on this, this paper proposes the method of minimum distance to the strong efficiency frontier that includes undesirable output.

Suppose that there are $\mathrm{m}$ production factors that are inputted in each of the $\mathrm{n}$ decision units in a production system, producing $s_{1}$ desirable outputs and $s_{2}$ undesirable outputs. Assume that $X=\left(x_{1}, x_{2}, \ldots, x_{n}\right) \in R_{+}^{m \times n}, Y^{g}=\left(y_{1}^{g}, y_{2}^{g} \ldots, y_{n}^{g}\right) \in R_{+}^{s_{1} \times n} \quad$ and $Y^{b}=\left(y_{1}^{b}, y_{2}^{b} \ldots, y_{n}^{b}\right) \in R_{+}^{s_{2} \times n}$ represent factor input, desirable output, and variants of undesirable output, respectively. Suppose that $D M U_{0}=\left(x_{0}, y_{0}^{g}, y_{0}^{b}\right)$ is the decision unit to be measured, that the production possibility set is expressed as $P^{t}\left({ }_{\mathrm{x}}\right)=\{(x, y): x$ can produce $y$, and that $F^{s}(P)$ is the strong efficiency frontier in the production possibility set. On the premise that minimum distance is $L_{1}$, the model of minimum distance to the strong efficiency frontier is expressed as follows.

$$
\begin{gathered}
(m S B M) \quad \min \left(\sum_{i=1}^{m} s_{i 0}^{-}+\sum_{r=1}^{s_{1}} s_{r 0}^{+}+\sum_{l=1}^{s_{2}} \bar{s}_{l 0}^{-}\right)+M\left(\sum_{i=1}^{m} \bar{s}_{i 0}^{-}+\sum_{r=1}^{s_{1}} \bar{s}_{r 0}^{+}+\sum_{l=1}^{s_{2}} \overline{s_{l 0}}\right) \\
s_{i 0}^{-} \geq 0, i=1, \ldots, m \\
s_{r 0}^{+} \geq 0, r=1, \ldots, s_{1} \\
s_{l 0}^{-} \geq 0, l=1, \ldots, s_{2} \\
\max \left(\sum_{i=1}^{m} \bar{s}_{i 0}^{-}+\sum_{r=1}^{s_{1}} \bar{s}_{r 0}^{+}+\sum_{l=1}^{s_{2}} \overline{s_{l 0}^{-}}\right) \\
\quad s . t . \quad \sum_{j \in E_{c}} \lambda_{j} x_{i j}+\bar{s}_{i 0}^{-}=x_{i 0}-s_{i 0}^{-} \\
\sum_{j \in E_{c}} \lambda_{j} y_{i j}^{g}-\bar{s}_{r 0}^{+}=y_{i 0}^{g}+s_{r 0}^{+} \\
\sum_{j \in E_{c}} \lambda_{j} y_{i j}^{b}+\bar{s}_{l 0}^{-}=y_{i 0}^{b}-\bar{s}_{l 0}^{-} \\
\lambda_{j} \geq 0, \bar{s}_{i 0}^{-} \geq 0, \bar{s}_{r 0}^{+} \geq 0, \bar{s}_{l 0}^{-} \geq 0
\end{gathered}
$$

where $s_{i 0}^{-}, s_{r 0}^{+}, s_{l 0}^{-}, \bar{s}_{i 0}^{-}, \bar{s}_{r 0}^{+}, \bar{s}_{l 0}^{-}$represents slack variables, and $\mathrm{M}$ is a positive number with a large value. The combination of equation (1) and equation (2) forms a typical bilevel linear programming, namely the so-called minimum distance to the 
strong efficiency frontier, or SBM of the minimum distance (mSBM). The reason why it is refered to as $\mathrm{mSBM}$ is that it is an optimal version of SBM. The research transforms equation (2) into the following equation.

$$
\min \left(\frac{1-\frac{1}{m} \sum_{i=1}^{m} \bar{s}_{i 0}^{-} / x_{i 0}}{1+\frac{1}{s_{1}+s_{2}}\left(\sum_{r=1}^{s_{1}} \bar{s}_{r 0}^{+} / y_{r 0}+\sum_{l=1}^{s_{2}} \bar{s}_{l 0}^{-} / b_{l 0}\right)}\right)
$$

The combination of equation (1) and equation (3) forms another bilevel linear programming, namely the SBM model. The maximization of $\sum_{i=1}^{m} \bar{s}_{i 0}^{-} / x_{i 0}, \sum_{r=1}^{s_{1}} \bar{s}_{r 0}^{+} / y_{r 0}$ and $\sum_{l=1}^{s_{2}} \bar{s}_{10} / b_{10}$ is the prerequisite for the construction of the SBM model. Generally, as $x_{i 0}, y_{r 0}$ and $b_{l 0}$ are constants, the research should then guarantee that the values of $\overline{s_{i 0}^{-}}, \bar{s}_{r 0}^{+}, \bar{s}_{l 0}^{-}$are as larger as possible, so that the value of equation (3), namely the constraints of the SBM model, is minimized. Therefore, it can be seen that the opposite side of mSBM is SBM. Compared with the SBM model, the most significant advantage of the mSBM model is that in the process of efficient improvement, the change amplitude of relaxation variables is the smallest. In reality, when evaluating the efficiency of an economic activity, the optimal allocation of resources can be achieved with the least variable cost, which is conducive to the production decision makers to make the optimal economic decision.

\subsubsection{The function of carbon dioxide emission performance}

If the minimum distance to the strong efficiency frontier is used to measure carbon dioxide emission efficiency, input factors and production results must be determined first. There are three input factors in this paper, namely capital stock, labor input, and energy consumption, represented by $\mathrm{K}, \mathrm{L}$ and $\mathrm{E}$, respectively. For output, there are desirable output (represented by y) and undesirable output (represented by b), denoting GDP and the amount of carbon dioxide emissions respectively of each province in China. This paper endows capital stock (K), labor input (L), energy consumption (E), GDP (y), and the amount of carbon dioxide emissions (b) with certain weights, which are $1 / 6,1 / 6,1 / 6,1 / 4$ and $1 / 4$, respectively. Referring to research achievements from Cooper et al. [28], the equations of input inefficiency, desirable output inefficiency, and undesirable output inefficiency are defined as follows.

Input inefficiency:

$I E_{x}=\frac{1}{2 m} \sum_{i=1}^{m} s_{i 0}^{-} / x_{i o}$

Desirable output inefficiency:

$I E_{y}=\frac{1}{4 s_{1}} \sum_{r=1}^{s_{1}} s_{r 0}^{y+} / y_{r 0}$

Undesirable output inefficiency:

$I E_{b}=\frac{1}{4 s_{2}} \sum_{l=1}^{s_{2}} s_{l 0}^{b-} / b_{l 0}$

where $s_{i 0}^{-} / x_{i 0}, \quad s_{r 0}^{y+} / y_{r 0}, \quad s_{l}^{b-} / b_{l 0}$ denote different adaptable percentages of slack variables.
Carbon dioxide emission performance is measured by substituting the results of expressions (4)-(6) into the following equation.

$$
C T E=\frac{1-I E_{X}}{1+I E_{y}+I E_{b}}
$$

\subsection{Convergence model}

\subsubsection{Traditional convergence model}

$\beta$ convergence is the most commonly used method in the convergence method, which is theoretically based on the assumption of economic growth convergence that result from diminishing marginal returns of capital. Specifically, it denotes the phenomenon that the economic growth rate of the region with a lower level of initial economic revenue would exceed that of the region with a higher level of initial economic revenue. As time passes, the economic revenue of the two regions would converge. The absolute $\beta$ convergence refers to the convergence trend between different regions free from the influence of external factors, while the conditional $\beta$ convergence refers to the convergence trend between different regions after taking into consideration the influence of external factors. Based on the convergence model proposed by Barro and Sala-i-Martin [29], the expression of the conditional $\beta$ convergence is as follows.

$\frac{1}{T} \ln \left(\frac{y_{i, t+T}}{y_{i, t}}\right)=\alpha+\beta \ln \left(y_{i, t}\right)+\varepsilon_{i, t} \quad \varepsilon \sim N\left(0, \sigma^{2}\right)$

where $y_{i, t+T}$ and $y_{i, t}$ denote the level of production at the moment of $\mathrm{t}+\mathrm{T}$ and $\mathrm{t}$ in region $I$, respectively; $\alpha$ is a constant; $\beta=-\left(1-e^{-\theta T}\right)$ and $\theta$ are the speed of convergence. For the regression results, if $\beta<0$, there is convergence of absolute $\beta$ in the period of $\mathrm{T}$, which means that the economic growth rate of underdeveloped areas is higher than that of advanced areas.

The conditional $\beta$ convergence factor in the control variables on the basis of absolute convergence. Its basic equation is follows.

$\frac{1}{T} \ln \left(\frac{y_{i, t+T}}{y_{i, t}}\right)=\alpha+\beta_{1} \ln \left(y_{i, t}\right)+\beta_{2} X_{i, t}+\varepsilon_{i, t} \quad \varepsilon \sim N\left(0, \sigma^{2}\right)$

\subsubsection{The convergence model with spatial effects}

Deviation in real measurement is possible for the above analysis of $\beta$ convergence because it is established on the basis of ordinary econometric methods which factor out spatial effects. Therefore, spatial effects are introduced into the ordinary convergence model and convergence research is conducted by establishing Spatial Autoregressive Model (SAR) and Spatial Error Model (SEM), respectively.

The convergence model of spatial autoregressive. In order to construct spatial panel data model, it is necessary to combine traditional convergence model with spatial econometric model. One of the representations of spatial econometric models is the SAR model. The basic equation of SAR is as follows [30].

$$
\left\{\begin{array}{l}
y=\rho W_{1} y+X \beta+u \\
u=\lambda W_{2}+\varepsilon \\
\varepsilon \sim N\left(0, \sigma_{\varepsilon}^{2} I_{n}\right)
\end{array}\right.
$$


where $y$ denotes the explained variables; $\rho$ and $\lambda$ denote the value of spatial autocorrelation coefficients, which are used to measure the degree of spatial dependence of the explained variables; $W$ denote the spatial weight matrix, which is commonly constructed by 0 and 1 of the $\mathrm{n} \times \mathrm{n}$ dimension; $W y$ denotes the spatial autocorrelation variable, which is used to measure the spatial strength of the spatial weight matrix; and $\varepsilon$ denotes random errors.

Based on equation (10), the equations of the spatial autocorrelation model of the absolute $\beta$ convergence and the conditional $\beta$ convergence are as follows after adding the spatial autocorrelation.

$\frac{1}{T} \ln \left(\frac{y_{i, t+T}}{y_{i, t}}\right)=\alpha+\beta \ln \left(y_{i, t}\right)+\rho W \ln \left(\frac{y_{i, t+T}}{y_{i, t}}\right)+\varepsilon_{i, t} \quad \varepsilon \sim N\left(0, \sigma^{2}\right)$

$\frac{1}{T} \ln \left(\frac{y_{i, t+T}}{y_{i, t}}\right)=\alpha+\beta_{1} \ln \left(y_{i, t}\right)+\beta_{2} X_{i, t}+\rho W \ln \left(\frac{y_{i, t+T}}{y_{i, t}}\right)+\varepsilon_{i, t} \quad \varepsilon \sim N\left(0, \sigma^{2}\right)$

Another form of spatial econometric model is the SEM model. The basic equation of SEM is as follows [31].

$$
\left\{\begin{array}{l}
y=X \beta+\varepsilon \\
u=\lambda W_{1} \varepsilon+u \\
\varepsilon \sim N\left(O, \sigma_{\varepsilon}^{2} I_{n}\right)
\end{array}\right.
$$

where $\lambda$ denotes the spatial error coefficient with $\mathrm{n} \times 1$ order, which is used to measure the spatial dependence of the residues; $\mu$ denotes random errors; $\beta$ denotes the regression coefficients that is computed by the model, which is used to reflect the causal connection of the explained variable $y$ and the explaining variable $X$; and $u$ denotes the stochastic disturbance that is uncorrelated with the space.

$\frac{1}{T} \ln \left(\frac{y_{i, t+T}}{y_{i, t}}\right)=\alpha+\beta \ln \left(y_{i, t}\right)+\varepsilon_{i, t} \quad \varepsilon_{i, t}=\lambda W+u, u \sim N\left(0, \sigma^{2} I\right)$

$\frac{1}{T} \ln \left(\frac{y_{i, t+T}}{y_{i, t}}\right)=\alpha+\beta_{1} \ln \left(y_{i, t}\right)+\beta_{2} X_{i, t}+\varepsilon_{i, t} \quad \varepsilon_{i, t}=\lambda W+u, u \sim N\left(0, \sigma^{2} I\right)$

\section{ASSESSMENT ON CARBON DIOXIDE EMISSION PERFORMANCE AND ANALYSIS ON SPATIAL CORRELATION}

\subsection{Description of variables and data resources}

Conceptual expounding should be done on the three input factors, namely capital stock, labor force and energy consumption, which are defined in the first section of the paper, as well as two of the production results of GDP and carbon dioxide emissions. Specifications are as follows: 1) Capital stock. According to research results of Shan [32], the equation of perpetual inventory method, namely $K_{i, t}=I_{i, t}+(1-\delta) K_{i, t-1}$, is used to measure the actual capital stock of each province each year, where $K_{i, t}$ denotes the capital stock at the th period of the ith province; $I_{i, t}$ denotes the investment at the th period of the ith province; and $\delta$ denotes the capital depreciation rate at the tth period of the ith province. The capital depreciation rate is $10.96 \%$. To eliminate the impact of prices, the equation is transferred into the actual capital stock according to the base price in 1952. 2) Labor force. Labor force refers to the unemployed or unemployed people who engage in social work and obtain labor remuneration or operating income, or who require work but have not yet obtained jobs. Internationally, the population between 15 and 64 years old is generally listed as labour force. Labor force is represented by the number of employees working at the end of the year in each province each year. 3) Energy consumption. It is the sum of consumption of primary energy including coal, gas and petroleum. To facilitate calculation, uniformed conversion is utilized with conversion coefficient of energy from the government, whose unit is ten thousand tons standard coal. 4) Real GDP. To determine the real GDP per year in each province, GDP deflator is used to transform nominal GDP into real GDP according to the base price in 1952. 5) $\mathrm{CO}_{2}$. The amount of emitted carbon dioxide is calculated according to the UN Framework Convention on Climate Change passed by IPCC (2006) and reference methods in Chapter 6, Volume II (Energy) of Guidelines for National Greenhouse Gas Inventories in Kyoto Protocol, which is expressed in the following equation.

$\mathrm{CO}_{2}=\sum_{i=1}^{3} E_{i} \times n N C V_{i} \times C E F_{i} \times C O F_{i} \times(44 / 12)$

where $\mathrm{CO}_{2}$ denotes the estimated amount of emitted carbon dioxide; $i=1,2,3$ denotes that the corresponding equation represents coal, petroleum and gas, respectively. $E$ denotes the amount of energy consumption, which is uniformly converted according to the conversion coefficient of energy from the government, its unit being ten thousand tons standard coal. $N C V$ denotes the net colorific value of energy; $C E F$ denotes the coefficient of carbon dioxide emissions; $C O F$ denotes the oxidant factor of coal; and 44 and 12 denote the molecular weight of carbon dioxide and carbon.

The panel data is chosen based on the principle of data comprehensiveness and availability from 30 provinces in China from 1998 to 2016. Tibet is excluded as its data is missing. All of the data herein comes from the China Statistical Yearbook, the China Energy Statistical Yearbook, and local statistical yearbooks.

\subsection{The average carbon dioxide emission performance in each province and the analysis of regional diversity}

Based on equations (1)-(7), and after operating DEA software, the average carbon emissions performance of 30 provinces in China from 1998 to 2016 is displayed in Figure 1, which shows that the average carbon emissions performance in Shanghai, Liaoning and Yunnan remain at 1, meaning that they are at the efficiency frontier; the average carbon emissions performance in Fujian, Tianjin, Hainan, Chongqing, and Zhejiang is beyond 0.85 , meaning that they are close to the frontier of efficiency; and that provinces such as Ningxia, Inner Mongolia, Xinjiang, Shanxi, and Guizhou are far from the best frontier. Insufficiency of average carbon emissions performance in some provinces means that their ineffective loss is high, and that the highest priority should be given to those provinces in implementing energy conservation and emissions reduction. Table 1 further reveals that regional differences of carbon emissions performance are significant. Specifically, provinces with high carbon emissions performance are located mostly in eastern coastal China, and provinces with low carbon emissions performance are located mostly in inner China. 


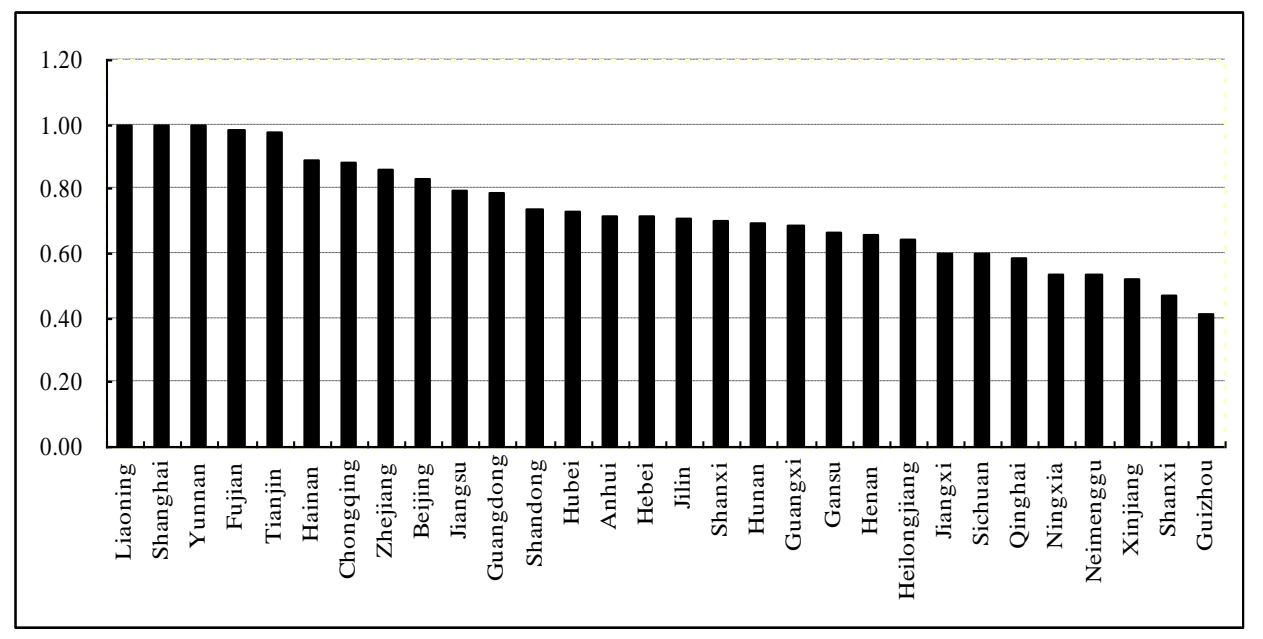

Figure 1. The average carbon emission performance in China

Figure 2 shows the trend of carbon emissions performance in eastern, central and western China, and the nationwide from 1998 to 2016, showing that the trends among them remain basically similar. Overall, they share a steady trend in the sample period. In addition, from the perspective of the average level of carbon emissions performance, regional diversity in eastern, central and western China is significant. The average level of carbon emissions performance in eastern China is 0.8426 , which is much higher than the average national level of 0.7040 . The average level of carbon emissions performance is 0.6283 in central China and 0.6206 in western China, which is much lower than the average national level. Therefore, there are apparent differences in carbon emissions performance among these three regions. In central and western China, there is a catch-up effect of carbon emissions performance compared to that in eastern China. This regional differentiation of carbon emission performance just confirms the Environmental Kuznets Curve (EKC): in the early stage of economic development, environmental pollution and per capita GDP are positively correlated; in the late stage of economic development, environmental pollution and per capita GDP are negatively correlated. Therefore, the carbon emission performance of the developed eastern region is significantly higher than that of the economically backward central and western regions of China.

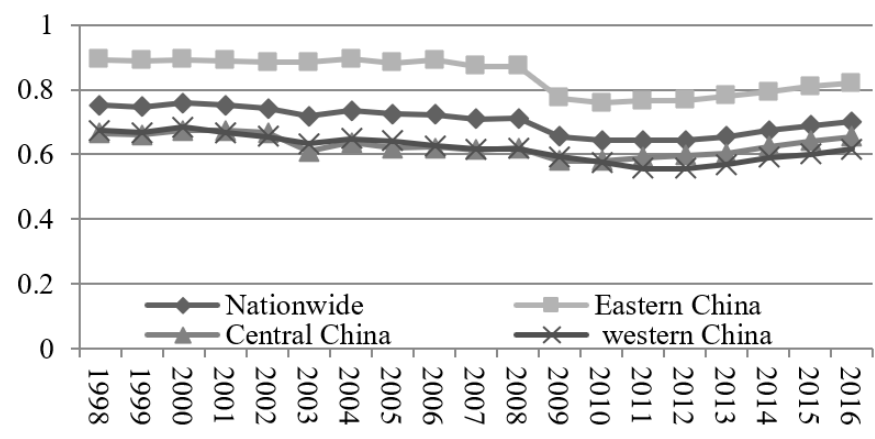

Figure 2. The trend of carbon emission performance in eastern, central, western China, and the nationwide

\subsection{Analysis of spatial correlation of regional carbon emissions performance}

There are mutual spatial effects in regional carbon dioxide emission efficiency, which are mainly reflected in spatial correlation and spatial heterogeneity. Spatial correlation means that there are spatial spillover and spatial diffusion in provincial carbon dioxide emissions. The nearer two regions are, the stronger effects they have. Spatial heterogeneity means that there is different carbon emissions performance in different elevations and between central regions and peripheral regions. Because of the spatial correlation or heterogeneity of carbon emission performance in geographic space, the traditional general measurement model can not be investigated. Therefore, it is necessary to establish a spatial effect model to accurately measure this important feature of carbon emission performance. The spatial effect model transforms the traditional ordinary data into spatial data, incorporates the important premise of spatial matrix, and uses the professional Geoda software to measure the spatial characteristics of the object under investigation, which plays an important role in improving the research value of carbon emission performance.

The spatial correlation can be represented by the index of global Moran's I. The expression of global Moran's I is as follows [33].

Moran's $I=\frac{n}{\sum_{i=1}^{n}\left(x_{i}-\bar{x}\right)^{2}} \frac{\sum_{i=1}^{n} \sum_{j=1}^{n} W_{i j}\left(x_{i}-\bar{x}\right)\left(x_{j}-\bar{x}\right)}{\sum_{i=1}^{n} \sum_{j=1}^{n} W_{i j}}$

where $n$ denotes the number of spatial units; $x_{i}$ and $x_{j}$ denote the observed value of the investigated value in the area of $I$ and in the area of $j \cdot \bar{x}=\left(\sum_{i} x_{i}\right) / n$ denotes the average value of the investigated value. $W_{i j}$ is the spatial weight matrix, which denotes the most basic spatial adjacent matrix herein.

$W_{i j}= \begin{cases}1 & \mathrm{i} \text { and } \mathrm{j} \text { are adjacent to each other } \\ 0 & \mathrm{i} \text { and } \mathrm{j} \text { are non }- \text { adjacent to each other }\end{cases}$

Generally, when the global Moran's I is computed, the expected value and variance should also be provided in order to further clarify related values and features of the index. The expression of the expected value is as follows.

$E_{n}($ Moran's $I)=-\frac{1}{n-1}$

And the expression of the variance is as follows. 
$\operatorname{Var}(M o r a n ' s \quad I)=\frac{n^{2} w_{1}+n w_{2}+3 w_{0}^{2}}{w_{0}^{2}\left(n^{2}-1\right)}-E_{n}^{2}($ Moran's I)

where $w_{0}=\sum_{i=1}^{n} \sum_{j=1}^{n} w_{i j}, w_{1}=\frac{1}{2} \sum_{i=1}^{n} \sum_{j=1}^{n}\left(w_{i j}+w_{j i}\right)^{2}, w_{2}=\sum_{i=1}^{n}\left(w_{i}+w_{i}\right)^{2}, w_{i}$ is equal to the sum of all the values of the spatial matrix in the $i$ th line, and $w_{. i}$ is equal to the sum of all the values of the spatial matrix in the $i$ th row.

After Moran's I is computed, its authenticity is tested by testing its significance. Under normal conditions, Z-score hypothesis of normal distribution is used in such a test, whose expression is as follows.

$Z(d)=\frac{[\text { Moran's } I-E(\text { Moran's } I)]}{\sqrt{\operatorname{VAR}(\text { Moran's } I)}}$

Generally, the global Moran's I ranges between -1 and 1 . An index of -1 means that the spatial feature of the investigated variant is totally negatively correlated. An index of 1 means that the spatial feature of the investigated variant is totally positively correlated. An index of 0 indicates no spatial correlation in the investigated variant. If the statistics of Zscore normal distribution of Moran's I pass the hypothesis testing with certain confidence levels $(10 \%, 5 \%$ or $1 \%)$, it is proved that Moran's I exists significantly.

The global Moran's I tests merely whether the objective has global spatial correlation, but fails to represent the features of spatial distribution of its interior. To address this, local indexes of spatial correlation, namely LISA, are introduced to represent the objective's spatial correlation. LISA is defined as spatial scatter program, describing the distribution of the objective in the four quadrants of the spatial coordinate system (H-H, L-H, L-L, and H-L). The expression of local Moran's I is as follows [34].

Moran's $I=\frac{n^{2}}{\sum_{i=1}^{n}\left(x_{i}-\bar{x}\right)^{2}} \frac{\left(x_{i}-\bar{x}\right) \sum_{i=1}^{n} \sum_{j=1}^{n} W_{i j}\left(x_{j}-\bar{x}\right)}{\sum_{i=1}^{n} \sum_{j=1}^{n} W_{i j}}$

Results of operating Geoda software. Table 1 shows the values of global Moran's I of regional carbon emissions performance in China from 1998 to 2016. It can be seen that all values of global Moran's I of regional carbon emissions performance are positive, and are significant at the $10 \%$-level. It clearly shows that provincial carbon emissions performance in China includes strong positive spatial correlation, which in turn exerts great influence on regional carbon emissions performance in China. Instead of being randomly distributed in space, carbon dioxide efficiency presents strong clump patterns. In addition, the Moran's I index shows an upward trend of fluctuation with time, indicating that the spatial effect of carbon emission performance is gradually strengthening. Thus, on the economic and environmental issues, the links between regions are becoming more and more closely. This reveals that when investigating the convergence of provincial carbon dioxide efficiency, spatial correlation should not be ignored; otherwise, severe deviations will arise in model estimation.
Table 1. Moran's I of regional carbon emissions performance in China from 1998 to 2016

\begin{tabular}{llllll}
\hline Year & Moran's I & E(I) & Mean & sd(I) & Z-value \\
\hline 1998 & 0.0954 & -0.0345 & -0.0367 & 0.1170 & $1.1103^{*}$ \\
1999 & 0.1264 & -0.0345 & -0.0388 & 0.1182 & $1.3613^{*}$ \\
2000 & 0.1011 & -0.0345 & -0.0419 & 0.1205 & $1.1253^{*}$ \\
2001 & 0.1159 & -0.0345 & -0.0392 & 0.1186 & $1.2681^{*}$ \\
2002 & 0.1272 & -0.0345 & -0.0408 & 0.1208 & $1.3386^{*}$ \\
2003 & 0.1176 & -0.0345 & -0.0388 & 0.1222 & $1.2447^{*}$ \\
2004 & 0.1077 & -0.0345 & -0.0412 & 0.1217 & $1.1684^{*}$ \\
2005 & 0.1438 & -0.0345 & -0.0443 & 0.1202 & $1.4834^{*}$ \\
2006 & 0.1352 & -0.0345 & -0.0411 & 0.1186 & $1.4309^{*}$ \\
2007 & 0.1266 & -0.0345 & -0.0371 & 0.1222 & $1.3183^{*}$ \\
2008 & 0.1423 & -0.0345 & -0.0377 & 0.1201 & $1.4721^{*}$ \\
2009 & 0.1450 & -0.0345 & -0.0416 & 0.1224 & $1.4665^{*}$ \\
2010 & 0.1256 & -0.0345 & -0.0378 & 0.1186 & $1.3499^{*}$ \\
2011 & 0.1255 & -0.0345 & -0.0456 & 0.1221 & $1.3104^{*}$ \\
2012 & 0.1314 & -0.0345 & -0.0448 & 0.1247 & $1.3304^{*}$ \\
2013 & 0.1327 & -0.0345 & -0.0419 & 0.1221 & $1.3694^{*}$ \\
2014 & 0.1337 & -0.0345 & -0.0424 & 0.1207 & $1.3935^{*}$ \\
2015 & 0.1384 & -0.0345 & -0.0397 & 0.1232 & $1.4034^{*}$ \\
2016 & 0.1403 & -0.0345 & -0.0426 & 0.1225 & $1.4269^{*}$ \\
\hline
\end{tabular}

Note: The*represents different tests with $10 \%$-level significance.

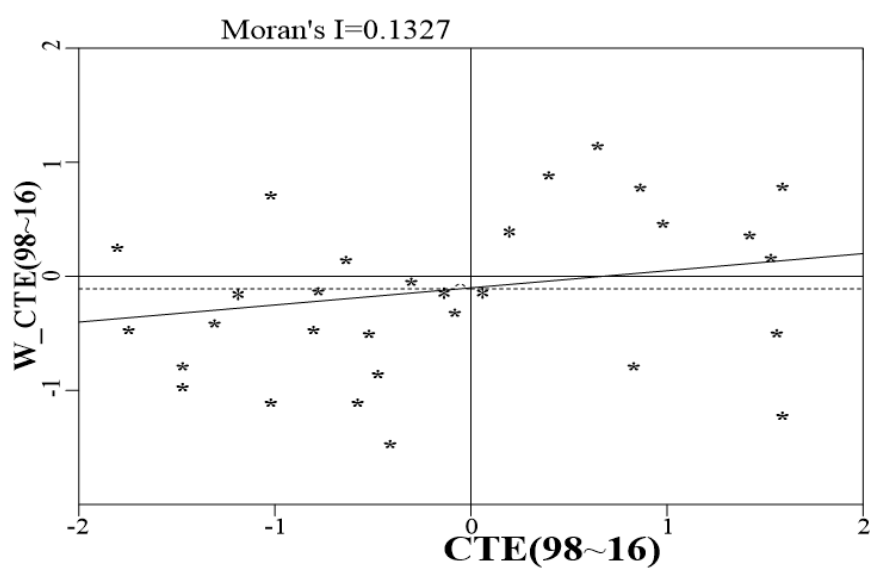

Figure 3. Moran's I scatter plot of carbon emissions performance in China

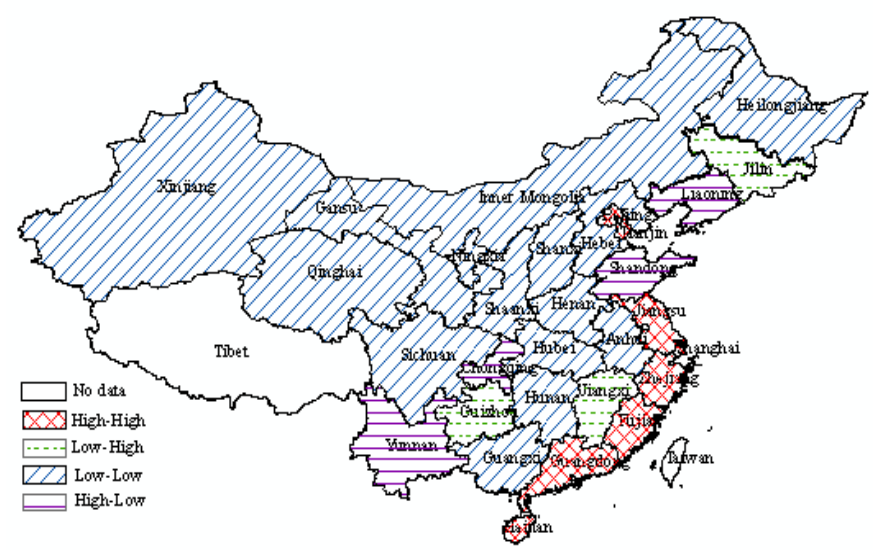

Figure 4. LISA map of of carbon emissions performance in China

Figure 3 and Figure 4 show LISA of the average regional carbon emissions performance in China from 1998 to 2016, showing a strong spatial correlation of carbon emissions performance in adjacent provinces in China. In Table 3, provinces at $\mathrm{H}-\mathrm{H}$ quadrant are those have high carbon emissions performance, and carbon emissions performance in 
their neighboring provinces is also high. According to spatial lagging index, Beijing, Tianjin, Zhejiang, Shanghai, Jiangsu, Hainan, Fujian, and Guangdong are at $\mathrm{H}-\mathrm{H}$ quadrant, occupying $26.67 \%$ of the total statistical units. Provinces at L$\mathrm{H}$ quadrant are those with low carbon emissions performance and high spatial lagging value. There are three provinces in this quadrant, namely Jilin, Guizhou and Jiangxi, occupying $10.00 \%$ of the total statistical units. Provinces at L-L quadrant are those with low carbon dioxide emission efficiency and low spatial lagging value. There are fifteen provinces in this quadrant, namely Hebei, Jilin, Heilongjiang, Inner Mongolia, Shanxi, Henan, Hubei, Hunan, Sichuan, Guangxi, Xinjiang, Gansu, Shaanxi, Qinghai, and Ningxia, occupying 50.00\% of the total statistic units. Provinces at H-L quadrant are those with high carbon dioxide emission efficiency and low spatial lagging value. There are only four provinces in this quadrant, namely Shandong, Liaoning, Chongqing and Yunnan, occupying $13.33 \%$ of the total statistical units. The provinces with strong spatial similarities lie in $\mathrm{H}-\mathrm{H}$ quadrant and L-L quadrant, whose percentage is $76.66 \%$. The provinces with different spatial autocorrelation lie in H-L quadrant and L-H quadrant, whose percentageis $23.33 \%$. Therefore, carbon emissions performance in China shows not only spatial dependence, but also spatial heterogeneity.

\section{INDICATORS AND DATA SOURCES}

In the first section of the paper, regional differences in carbon emissions performance in China have been studied. To render the research more practical, it is necessary to conduct further empirical analysis on whether there is convergence. With regard to carbon emissions performance, the absolute $\beta$ convergence and the conditional $\beta$ convergence have been researched. The first is relatively simple as it excludes external factors. However, as the economic condition is weaker, and in order to render the research more practical, it is necessary to fully invetigate influencing factors on convergences, thus forming the conditional $\beta$ convergence. In recent years, research on influencing factors on convergence of carbon emissions performance has remained prevelant in the academic field, with various analyses being carried out from different perspectives. Based on existing research, this paper holds that the main factors that influence convergence of carbon dioxide emission efficiency are economical scale [35], industrial structure [36], energy consumption structure [37], governmental intervention [38], FDI [39], and technological advances [40].

Because the data used in this paper are from the panel data of 30 provinces in China, it is necessary to make a choice between fixed effect and random effect in the regression process of the model. The former refers to the important influence of individual effect on regression variables, while the latter refers to the absence of any influence between the two. Since this paper is an empirical study from the perspective of individual effects, the best choice of the model is fixed effects rather than random effects. Based on equations (8)-(15), the models of absolute $\beta$ convergence and conditional $\beta$ convergence are established, respectively, with each factoring in the spatial effect.

The model of absolute $\beta$ convergence is:

$$
\begin{aligned}
& g \operatorname{CTE}_{i, t}=\alpha_{i}+\phi_{t}+\beta \operatorname{Ln}\left(C T E_{i, t-1}\right)+\delta \sum_{j} W_{i j}\left(g C T E_{i, t}\right)+\mu_{i, t} \\
& \mu_{i, t}=\lambda \sum_{j} W_{i j} * u_{i, t}+\varepsilon_{i, t}
\end{aligned}
$$

The model of conditional $\beta$ convergence is:

$$
\begin{aligned}
& g C T E_{i, t}=\alpha_{i}+\phi_{t}+\beta_{1} \operatorname{Ln}\left(C T E_{i, t-1}\right)+\beta_{2} X_{i, t}+\delta \sum_{j} W_{i j}\left(g C T E_{i, t}\right)+\mu_{i, t} \\
& \mu_{i, t}=\lambda \sum_{j} W_{i j} * u_{i, t}+\varepsilon_{i, t}
\end{aligned}
$$

It is an ordinary space-fixed effect model, where $\delta$ and $\lambda$ denote the coefficient of spatial correlation and the coefficient of spatial error, respectively. When $\delta$ equals zero, the model transform to SEM; and when $\lambda$ equals zero, the model transform to SAR. $\alpha_{i}$ and $\emptyset_{t}$ denote space-fixed effect and time-fixed effect, respectively.

In equation (23), $g C T E_{i, t}$ denotes the growth speed of carbon emissions performance at the $t$ th year in $i$ province. $\operatorname{Ln}\left(C T E_{i, t}\right.$. l) denotes the natural logarithm of carbon emissions performance at the $t$ - 1 th year in $i$ province. $X_{i, t}$ denotes the set of control variables herein. $\mu i, t$ denotes the random error terms. Explanations of the indexes are as follows.

$g C T E_{i, t}$ : the index of growth rate of regional carbon emissions performance, denoted by the subtraction of the logarithm of carbon emissions performance at the $t$ - 1 th year in $i$ province from that at the $t$ th year in $i$ province, namely $g C T E_{i, t}=\Delta \operatorname{Ln}\left(C T E_{i, t}\right)=\operatorname{Ln}\left(C T E_{i, t}\right)-\operatorname{Ln}\left(C T E_{i, t-1}\right)$.

$\operatorname{Ln}\left(C T E_{i, t-1}\right)$ : the index of the provincial carbon dioxide emission efficiency at the initial period, denoted by the logarithm of carbon emissions performance at the $t$ - 1 th year in $i$ province. Whether there is convergence in the provincial carbon emissions performance is determined by whether the coefficient of variables is positive or not. If the coefficient is apparently negative, it shows that the increase of carbon emissions performance demonstrates an apparent trend of $\beta$ convergence.

The control variables to be investigated herein include:

$G D P_{i, t}$, the index of economic scale, denoted by the natural logarithm of nominal GDP at the $t$ th year for $i$ province; $I N D_{i, t}$, the index of industrial structure, denoted by the weight of add value in the tertiary industry in $G D P ; F D I_{i, t}$, namely the index of foreign direct investment; $G O V_{i, t}$, the index of governmental intervention, denoted by the weight of fiscal expenditure of all provinces in GDP; $E C S_{i, t}$, the index of energy consumption structure, denoted by the weight of coal consumption in the total sum of energy consumption; $T E G_{i, t}$, the index of technological advance, denoted by the applied panel approval of all provinces.

Given the comprehensiveness and availability of data, this paper adopts the panel data of 30 provincial regions from 1998 to 2016 as its objective. All of such data is derived from the China Statistical Yearbook, the China Energy Statistical Yearbook, the Statistical Yearbook of Science and Technology of China, China Compendium of Statistics 1949-2008, and local statistical yearbooks.

\section{EMPIRICAL RESULTS AND EXPLANATION}

\subsection{The econometric results of the ordinary panel data model and tests on spatial correlation}

This research project first conducts simulations of equations (23) and (24) with the ordinary panel data model, as well as testing on spatial correlation of regression residuals, whose results are shown in Table 2 below. Table 2 also includes the estimation results of the mixed panel model, the space-fixed effect model, the time-fixed effect model, and the two-way 
fixed effect model. The necessity of the control model with fixed effect is demonstrated through comparison of the test data.

Table 2 shows that for the absolute $\beta$ convergence, the coefficient of determination on suitability of the two-way fixed effect model is 0.0035 ; and after the space-fixed effect model and the time-fixed effect model are added, the coefficient of such increases to 0.0785 . Similarly, the coefficient of determination on suitability in the two-way fixed effect model is the largest in the conditional $\beta$ convergence. It can be seen that the coefficient of determination of suitability of the two-way fixed effect model is the largest among all four models both in the model of absolute $\beta$ convergence and conditional $\beta$ convergence. Compared with the log-likelihood functions of the four econometric models, the log-likelihood functions of the two-way fixed effect model are the largest both in the model of absolute $\beta$ convergence at 820.1634 and in the model of conditional $\beta$ convergence at 847.8410 . This shows that the two-way fixed effect model is better than the other models. Therefore, the econometric results of the twoway fixed effect model is used herein to explain the convergence of provincial carbon emissions performance in China [41].

Table 2. The estimation and test results of the ordinary panel data mode

\begin{tabular}{|c|c|c|c|c|c|c|c|c|}
\hline \multirow[b]{2}{*}{ Variables } & \multicolumn{4}{|c|}{ Absolute $\beta$ convergence } & \multicolumn{4}{|c|}{ Conditional $\beta$ convergence } \\
\hline & Mixed & $\begin{array}{c}\text { Space-fixed } \\
\text { effect }\end{array}$ & $\begin{array}{c}\text { Time-fixed } \\
\text { effect }\end{array}$ & $\begin{array}{c}\text { two-way fixed } \\
\text { effect }\end{array}$ & Mixed & $\begin{array}{c}\text { Space-fixed } \\
\text { effect }\end{array}$ & $\begin{array}{c}\text { Time-fixed } \\
\text { effect }\end{array}$ & $\begin{array}{c}\text { Two-way fixed } \\
\text { effect }\end{array}$ \\
\hline$C T E_{i, t-1}$ & $\begin{array}{c}0.0098 \\
(1.1663)\end{array}$ & $\begin{array}{c}-0.1252 * * * \\
(-4.3931)\end{array}$ & $\begin{array}{c}0.0092 \\
(1.2071)\end{array}$ & $\begin{array}{c}-0.1793 * * * \\
(-5.9309)\end{array}$ & $\begin{array}{l}-0.0252 * \\
(-1.9043)\end{array}$ & $\begin{array}{c}-0.2974 * * * \\
(-8.7532)\end{array}$ & $\begin{array}{l}-0.0172 * \\
(-1.6048)\end{array}$ & $\begin{array}{c}-0.3294 * * * \\
(-9.1943)\end{array}$ \\
\hline$G D P$ & & & & & $\begin{array}{l}-0.0093^{*} \\
(-1.4986)\end{array}$ & $\begin{array}{c}-0.0464 * * * \\
(-4.5379)\end{array}$ & $\begin{array}{l}-0.0038 \\
(-0.4832)\end{array}$ & $\begin{array}{c}-0.1128 * * * \\
(-4.1834)\end{array}$ \\
\hline$I N D$ & & & & & $\begin{array}{c}-0.0042 \\
(-0.1329)\end{array}$ & $\begin{array}{c}0.1346 * * \\
(2.1942)\end{array}$ & $\begin{array}{l}-0.0058 \\
(-0.1704)\end{array}$ & $\begin{array}{l}0.0898 * \\
(1.6352)\end{array}$ \\
\hline$F D I$ & & & & & $\begin{array}{c}0.0142 \\
(0.1403)\end{array}$ & $\begin{array}{c}0.1192 \\
(0.8391)\end{array}$ & $\begin{array}{c}0.0141 \\
(0.1496)\end{array}$ & $\begin{array}{c}0.1395 \\
(0.9979)\end{array}$ \\
\hline$G O V$ & & & & & $\begin{array}{c}-0.0992 * * * \\
(-3.5038)\end{array}$ & $\begin{array}{c}-0.0872 \\
(-1.4932)\end{array}$ & $\begin{array}{c}-0.0242 \\
(-0.5127)\end{array}$ & $\begin{array}{l}-0.0745^{*} \\
(-1.7971)\end{array}$ \\
\hline$E C S$ & & & & & $\begin{array}{l}-0.0251 * * \\
(-2.2574)\end{array}$ & $\begin{array}{c}-0.1386 * * * \\
(-5.8473)\end{array}$ & $\begin{array}{c}-0.0198 * * \\
(-2.0211)\end{array}$ & $\begin{array}{c}-0.1326 * * * \\
(-5.5757)\end{array}$ \\
\hline$T E G$ & & & & & $\begin{array}{l}0.0072 * \\
(1.5968)\end{array}$ & $\begin{array}{c}0.0239 * * * \\
(3.4947)\end{array}$ & $\begin{array}{c}0.0063 \\
(1.4031)\end{array}$ & $\begin{array}{c}0.0239 * * * \\
(3.5049)\end{array}$ \\
\hline$R$-squared & 0.0035 & 0.0435 & 0.0032 & 0.0793 & 0.0477 & 0.2132 & 0.0363 & 0.3285 \\
\hline $\log -L$ & 758.5103 & 782.2611 & 787.8265 & 820.1634 & 768.2846 & 821.8473 & 794.8522 & 847.8410 \\
\hline$D W$ & 1.5796 & 1.5404 & 1.7862 & 1.7885 & 1.7039 & 1.6374 & 1.8174 & 1.7905 \\
\hline LM-sar & $36.1134 * * *$ & $44.2018 * * *$ & $6.3845 * * *$ & $7.0237 * * *$ & $30.3864 * * *$ & $32.3841 * * *$ & $5.5391 * * *$ & $7.1035 * * *$ \\
\hline Robust LM-sar & 0.5874 & $6.0182 * *$ & 0.4273 & 0.3269 & $4.4862 * *$ & 1.5449 & 1.3964 & 0.0329 \\
\hline LM-err & $35.5194 * * *$ & $52.4372 * * *$ & $6.2164 * * *$ & $8.1892 * * *$ & $27.2975 * * *$ & $31.3842 * * *$ & $4.9582 * * *$ & $7.4395 * * *$ \\
\hline Robust LM-err & 0.7016 & $14.2744 * * *$ & 0.3262 & $1.5237^{*}$ & $2.2184 *$ & 0.1429 & 0.8048 & 0.4013 \\
\hline
\end{tabular}

Note: the data in the brackets denote $\mathrm{T}$ test value. $*, * *, * * *$ represent the level of significance at $10 \%, 5 \%$, and $1 \%$, respectively.Matlab7.11 is used for model estimation and tests on spatial autocorrelation

The latter section of Table 2 shows the test results of spatial correlation in the original panel data model. The value of $L M$ sar in the two-way fixed effect model in the absolute $\beta$ convergence is 7.1035 , and the value of $L M$-err is 8.1892 , both of which pass the $1 \%$-level test of significance. The above results show that the estimation results of the two models have significant spatial correlation. Meanwhile, the statistics in LMerr exceed those in LM-sar in both the two-way fixed effect models. Thus, by comparison, the spatial error model is chosen for its form of spatial correlation model.

\subsection{Estimated results of the spatial panel data model}

Given that there is an apparent spatial autocorrelation in the ordinary panel model, the method of spatial econometrics is used to start a second simulation on the model, and the models of SAR and SEM are acquired, which are shown in Table 3. It can be seen that compared to the original panel data model, the coefficient of determination of suitability for the spatial model is substantially improved, and so is $\log -L$, the log-likelihood function. In addition, there is also some improvement on the $\mathrm{T}$ value of regression result that is tested by the spatial model. This shows that the regression result of the spatial econometric model is well modified to be more accurate than that of the original panel data model. The fact that $L o g-L$ of the SEM model is larger than that of the SAR model in either the absolute $\beta$ convergence model or the conditional $\beta$ convergence model shows that the SEM model offers a more complete explanation than the SAR model. Therefore, this paper employs the results of each of the explanatory variables in the SEM model principally for its explanation and analysis.

The coefficient of $\operatorname{Ln}\left(C T E_{t-1}\right)$ is negative, and passes the $1 \%$ level of significance test in the absolute $\beta$ convergence model. This shows that there is an apparent absolute $\beta$ convergence in the provincial levels of carbon emissions performance in China. With the equation of $\beta^{-}$convergence of the neoclassical economic growth model, it can be determined that the speed of absolute convergence of provincial carbon emissions performance in China within the sample period is $1.11 \%$, recording a substantial increase compared to the speed in the original panel model, which is $1.04 \%$. This shows that the speed of absolute convergence of regional carbon emissions performance rises greatly when factoring in the spatial effect. At the same time, this also effectively confirms that China's provincial carbon emission performance has a significant spatial spillover effect. The change of carbon emission performance in a province will be positively influenced by the carbon emission performance of other provinces. Therefore, after the spatial effect is incorporated, the absolute convergent rate of carbon emission performance will accelerate. 
Table 3. Estimation and test results of the spatial econometric model with two-way fixed effects

\begin{tabular}{|c|c|c|c|c|}
\hline \multirow{2}{*}{ Variables } & \multicolumn{2}{|c|}{ Absolute $\beta$ convergence } & \multicolumn{2}{|c|}{ Conditional $\beta$ convergence } \\
\hline & $S A R$ & SEM & $S A R$ & SEM \\
\hline $\operatorname{Ln}\left(C T E_{i-1}\right)$ & $\begin{array}{c}-0.1801 * * * * \\
(-6.0384)\end{array}$ & $\begin{array}{c}-0.1892 * * * \\
(-6.2394)\end{array}$ & $\begin{array}{r}-0.3398 * * * \\
(-9.4936)\end{array}$ & $\begin{array}{c}-0.3430 * * * \\
(-9.5962)\end{array}$ \\
\hline$G D P$ & & & $\begin{array}{c}-0.1284 * * * \\
(-4.4973)\end{array}$ & $\begin{array}{c}-0.1301 * * * \\
(-4.6482)\end{array}$ \\
\hline$I N D$ & & & $\begin{array}{l}0.0899^{*} \\
(1.7495)\end{array}$ & $\begin{array}{l}0.0904^{*} \\
(1.7958)\end{array}$ \\
\hline FDI & & & $\begin{array}{c}0.1305 \\
(0.9824)\end{array}$ & $\begin{array}{c}0.0893 \\
(0.6531)\end{array}$ \\
\hline GOV & & & $\begin{array}{l}-0.0763^{*} \\
(-1.8593)\end{array}$ & $\begin{array}{c}-0.0775^{* *} \\
(-1.9061)\end{array}$ \\
\hline$E C S$ & & & $\begin{array}{c}-0.1361 * * * \\
(-5.7434)\end{array}$ & $\begin{array}{c}-0.1432 * * * \\
(-5.9501)\end{array}$ \\
\hline$T E G$ & & & $\begin{array}{c}0.0218 * * * \\
(3.2845)\end{array}$ & $\begin{array}{c}0.0209 * * * \\
(3.1945)\end{array}$ \\
\hline $\mathrm{W}^{*}$ dep.var. & $\begin{array}{c}0.1785^{* * *} \\
(2.9031)\end{array}$ & & $\begin{array}{r}0.1692 * * * \\
(2.9041)\end{array}$ & \\
\hline spat.aut. & & $\begin{array}{c}0.1910 * * * \\
(3.1953)\end{array}$ & & $\begin{array}{c}0.1937 * * * \\
(3.1945)\end{array}$ \\
\hline $\begin{array}{c}R \text {-squared } \\
\text { Log-L }\end{array}$ & $\begin{array}{c}0.2805 \\
825.3975\end{array}$ & $\begin{array}{c}0.2853 \\
828.7391\end{array}$ & $\begin{array}{c}0.3749 \\
859.8491\end{array}$ & $\begin{array}{c}0.3841 \\
862.9513\end{array}$ \\
\hline
\end{tabular}

Compared to the results of the absolute $\beta$ convergence, the explanatory strength of the regression model with conditional $\beta$ convergence increases slightly after control variables are added in. When other variables are controlled, the coefficient of $\operatorname{Ln}\left(C T E_{t-1}\right)$ is negative, and passes the $1 \%$-level of significance test in the SEM model with conditional $\beta$ convergence. The speed of convergence computed by the equation of $\beta$ convergence is $2.21 \%$. Except for FDI, control variables such as economic scale, industrial structure, governmental intervention, structure of energy consumption, and technological advancements exert influences on the improvement of provincial carbon emissions performance in China from the following various perspectives.

Economic scale: The influence of GDP on the convergence of carbon emissions performance is negative. Current economic growth in China is motivated by a substantial increase in the absolute amount of production. Statistics show that, as a result of domestic economic growth, the total consumption of coal as a primary energy source in 2016 was 4.36 billion tons, accounting for $23 \%$ of total global energy consumption.

Industrial structure: IND has a positive influence on carbon emissions performance at the $1 \%$-level significance. Currently, China is working to intensify structural adjustments to industry and to optimize and upgrade industrial structure by greatly developing low-carbon industries such as finance, information, consultancy and technology. The percentage of tertiary industry in GDP increased from $23.9 \%$ in 1978 to $55.2 \%$ in 2016. The gap of industrial structure between regions will be further narrowed, especially under the national strategy to initiate industrial optimization. This will significantly drive the convergence of carbon emission performance.

$F D I$ : The estimation coefficient of FDI fails to pass the significance test. Perhaps the reason is that the process of attracting foreign investment into China facilitates the introduction of advanced technical equipment and management experience from foreign countries, thus increasing the efficiency of energy utilization and reducing the amount of carbon dioxide emissions. However, various regions differ greatly in the level of introduction of foreign investment. In 2016, for example, the sum of foreign investment introduced to eastern China occupies over $60 \%$ of the total domestic FDI, whereas the sum of foreign investment introduced to central and western China is less than $40 \%$ of the total domestic FDI. Therefore, the estimation coefficient of FDI is insignificant.

Governmental intervention: $G O V$ has a negative influence on carbon emissions performance at the $1 \%$-level significance. Perhaps the reason is that there are great differences in regional shares of the governmental fiscal expenditure. The data show that the governmental fiscal expenditure in eastern China is 7246.154 billion yuan in 2016 , accounting for $45.64 \%$ of the total fiscal expenditure. The governmental fiscal expenditure in central China is 4158.852 billion yuan, accounting for $26.20 \%$ of the total fiscal expenditure. The governmental fiscal expenditure in western China is 4470.332 billion yuan, accounting for $28.16 \%$. Especially when the system of tax distribution is reformed, the gaps among local fiscal expenditures are further enlarged. Furthermore, the intensification of governmental intervention would reduce the efficiency of resource allocation.

The structure of energy consumption: ECS has a negative influence on carbon emissions performance at the $5 \%$-level significance. The reason is that as the primary type of energy source for major countries all over the world is fossil energy, China maintains its absolute dominant position globally in the consumption of coal. In 2016, coal consumption still occupied $62 \%$ of total energy consumption in China, whereas hydro energy and other renewable energy resources accounted for less than $7 \%$. Meanwhile, restricted by regional differences in economy, technology and policies, coal consumption in China exhibits strong regional diversity, which tends to expand further. This has apparently exerted a negative influence on narrowing the gap among regions in carbon emissions performance.

Technological advance: $T E G$ has an apparent positive influence on the convergence of regional carbon emissions performance. With regional technological advancements, factors can be substituted. This can not only potentially lower energy intensification, but also facilitate the improvement of 
energy utilization efficiency. Data show that the energy intensity of China's unit GDP dropped from 1.74 in 1998 to 0.58 in 2016 . This fully shows that China's energy utilization level is constantly improving due to technological progress. Meanwhile, as there are always strong diffusing effects with technological advancement, advancements in one region would apparently facilitate that in another region, thus exerting a positive influence on the convergence of regional carbon emission performance.

\section{CONCLUSIONS}

Based on minimum distance to the strong efficiency frontier, this paper first constructs the function of carbon dioxide emissions to calculate the carbon dioxide emission efficiency from 1998 to 2016 for all provinces in China. Next, from this data, regional differences and spatial correlation of carbon emissions performance are analyzed. Finally, a spatial econometric model is constructed to conduct empiricalstudy on the convergence of regional carbon dioxide emission efficiency. Conclusions are as follows.

First, calculation results of the average carbon emissions performance for all provinces show that provinces with high carbon emissions performance are mainly distributed in economically developed eastern coastal areas, and that provinces with low carbon emissions performance are mainly distributed in economically underdeveloped inland areas. When considering the three economic regions in China separately in this regard, it is evident that the trend of carbon emissions performance among the various areas is relatively steady, and that the trend of carbon emissions performance in eastern areas is prominently higher than that in central and western areas.

Next, according to Moran's I indexes, there is an apparent spatial correlation and obvious cluster phenomenon in carbon emissions performance between regions. LISA shows that spatial dependences of carbon emissions performance exist in most of the provinces in China, but spatial differences exist in only a few of the remaining provinces.

Finally, it can be seen from the estimated results of the spatial econometric model that there are both absolute $\beta$ convergence and conditional $\beta$ convergence in provincial carbon emissions performance from 1998 to 2016 . Beyond the obvious influence of the "reform and opening up" policy, the convergence of carbon emissions performance is significantly influenced by factors such as economic scale, industrial structure, governmental intervention, energy structure, and technology advancements.

Through the above research conclusions, China should focus on changing the economic development model and adjusting the industrial structure and energy consumption structure for the future improvement of carbon emissions performance,. Specific measures include: first, we should adhere to the strategy of sustainable economic development, and promote the transformation of economic development from extensive mode to intensive mode. Second, the government should also promote the "retreat two into three" industrial restructuring strategy to achieve the optimization and upgrading of industrial structure step by step. Thirdly, the government should raise the level of foreign capital introduction, set up the environmental protection threshold of high standard foreign capital utilization, and further strengthen the screening of foreign capital technology. Fourth, we should increase the proportion of green energy consumption, such as water, wind and solar energy, and reduce the proportion of China's traditional coal-based fossil energy consumption. Fifth, the government should gradually reduce administrative intervention measures and establish a sound energy saving and emission reduction mechanism.

\section{ACKNOWLEDGMENT}

This paper was supported Humanities and social science research project of Chongqing Social Science Planning Project (No.2017BS34) and Chongqing Municipal Education Commission (No. 17SKG146).

\section{REFERENCES}

[1] Shretha RM, Timisina GR. (1996). Factors affecting $\mathrm{CO} 2$ inttensities of power sector in Asia: A division docoposition analysis. The Energy Economics 18(4): 283-293. https://doi.org/10.1016/S0140-9883(96)000199

[2] Fan Y, Liu LC, Wu G, Tsai HT, Wei YM. (2007). Changes in carbon intensity in China: Empirical findings from 1980-2003. Ecological Economics 62(3): 683-691. https://doi.org/10.1016/j.ecolecon.2006.08.016

[3] Mielnik O, Goldemberg J. (1999). Communication the evolution of the "carbonization index" in developing countries. Energy Policy 27(5): 307-308. https://doi.org/10.1016/S0301-4215(99)00018-X

[4] Sun JW. (2005). The decrease of $\mathrm{CO}_{2}$ emission intensity is decarbonization at national and global levels. Energy $\begin{array}{lll}\text { Policy 33(8): 957-978. } & \text { 3 }\end{array}$ https://doi.org/10.1016/j.enpol.2003.10.023

[5] Reinhard S, Thijssen GJ. (2000). Environmental efficiency with multiple environmentally detrimental variables; estimated with SFA and DEA. European Journal of Operational Research 121(2): 287-303. https://doi.org/10.1016/S0377-2217(99)00218-0

[6] Ourahmoune R, Salvia M, Mathia TG. (2016). Fatigue life analysis of adhesively bonded CFR-PEEK composites using acoustic emission monitoring. Revue des Composites et des Materiaux Avances 26(1): 45-62.

[7] Wang B, Wu Y, Yan P. (2010). Environmental efficiency and environmental total factor productivity growth in China's regional economics. Economic Research Journal 45(5): 95-109. http: //doi.org/erj.cn/english.asp

[8] Hua F. (2018). Carbon emission performance in chinese extractive industry based on stochastic frontier model and stochastic convergence test. Chemical Engineering Transactions 66: 523-528. https://doi.org/10.3303/CET1866088

[9] Zhou P, Ang BW, Han JY. (2010). Total factor carbon emission performance: A malmquist index analysis. Energy Economics 32(1): 194-201. https://doi.org/10.1016/j.eneco.2009.10.003

[10] Zaim O, Taskin F. (2000) . Environmental efficiency in carbon dioxide emissions in the OECD a non-parametric approach. Journal of Environmental Management 58(2): 95-107. https://doi.org/10.1006/jema.1999.0313

[11] Zofio JL, Prieto AM. (2001). Environmental efficiency and regulatory standards: The case of $\mathrm{CO}_{2}$ emissions from OECD industries. Resource and Energy Economics 
23(1): $\quad$ 63-81. https://doi.org/10.1016/S09287655(00)00030-0

[12] Marklund PO, Samakovlis E. (2007). What is driving the EU burden-sharing agreement efficiency or equity. Journal of Environmental Management 85(2): 317-329. https://doi.org/10.1016/j.jenvman.2006.09.017

[13] Wei M, Cao MF. Jiang JR. (2010). Determinants of longrun carbon emission performance. Quantitative and Technical Economics Research 27(9): 43-52. https://doi.org/0.13653/j.cnki.jqte.2010.09.001

[14] Risto H, Rajeev K, Goel. (2012). Global CO2 efficiency: country-wise estimates using a stochastic cost frontier. Energy Policy 45(7): 762-770. https://doi.org/10.1016/j.enpol.2012.03.007

[15] Zhao GH, Li W, Zhang RX, Liang WQ. (2012). Evaluation of carbon emission efficiency for Shanxi: Using stochastic frontier analysis. Resources Science, 34(10): 1966-1971. http://doi.org/10.7588 /j.cnki.re.2012.10.007

[16] Strazicich MC, List JA. (2003). Are CO2 emission levels converging among industrial countries. Environmental and Resource Economics 24(3): 263-271 http://doi.org/10.1023/A:1022910701857

[17] Aldy JE. (2006) Per capita carbon dioxide emissions: Convergence or divergence. Environmental Resource Economics 33(4): 533-555. http://doi.org/10.2139/ssrn.881086

[18] Romero-avila D. (2008). Convergence in carbon dioxide emissions among industrialized countries revisited. Energy Economics 30(5): 2265-2282. https://doi.org/10.1016/j.eneco.2007.06.003

[19] Jobert T, Karan F, Tykhonenko A. (2010). Convergence of per capita carbon dioxide emissions in the EU: Legend or reality. Energy Economics 32(6): 1364-1373. https://doi.org/10.1016/j.eneco.2010.03.005

[20] Westerlund J, Basher SA. (2008). Testing for convergence in carbon dioxide emissions using a century of panel data. Environmental and Resource Economics 40(1): 109-120. https://doi.org/10.1007/s10640-0079143-2

[21] Panopoulou E, Pantelidis T. (2009). Club convergence in carbon dioxide emissions. Environmental and Resource Economics 44(1): 47-70.

[22] Zhou WQ, Nie M. (2012). Regional differences in the efficiency of industrial carbon emissions in China: Based on the empirical analysis of non-parametric frontier. Quantitative and Technical Economics Research 29(9): 58-70. https://doi.org/10.13653/j.cnki.jqte.2012.09.007

[23] Wang QW, Zhou P, Zhou DQ. (2010). Research on dynamic carbon dioxide emissions performance, Regional disparity and affecting factors in China. China Industrial Economics 262(1): 45-54 https://doi.org/10.19581/j.cnki.ciejournal.2010.01.004

[24] Du HB, Wang YY. (2013). Total-Factor $\mathrm{CO}_{2}$ emission performance and the convergence hypothesis in China. Journal of Systems Engineeing 28(1): 257-264. https://doi.org/10.5781 /j.cnki.jse.2013. 02. 009

[25] Tobler WR. (1979). Philosophy in geography. Theory and Decision Library 20(1): 379-386.

[26] Jahanshahloo GR, Vakili J, Zarepisheh M. (2012). A linear bilevel programming problem for obtaining the closest targets and minimum distance of a unit from the strong efficient frontier. Asia-Pacific Journal of
Operational Research 29(2):

$1-19$.

https://doi.org/10.1142/S021759591250011X

[27] Aparicio J, Ruiz JL, Sirvent I. (2007). Closest targets and minimum distance to the pareto-efficient frontier in DEA. Journal of Productivity Analysis 28(3): 209-218. https://doi.org/10.1007/s11123-007-0039-5

[28] Cooper WW, Ruiz JL, Sirvent I. (2007). Choosing weights from alternative optimal solutions of dual multiplier models in DEA. European Journal of Operational Research H 180(1): 443-458. https://doi.org/10.1016/j.ejor.2006.02.037

[29] Barro RJ, Sala-i-Martin X. (2011). Convergence across states and regions. Brookings Papers on Economic Activity 100(1): 107-182. https://doi.org/10.2307/2534639

[30] Haining RP. (1993). Spatial data analysis in the social and environmental sciences. London: Cambridge University Press 18(4): 287-288.

[31] Griffith DA.(1988). Spatial econometrics: Methods and models. Economic Geography 65(2): 160-162. https://doi.org/10.2307/143780

[32] Shan HJ. (2008). Reestimating the capital stock of China: 1952-2006. Quantitative and Technical Economics Research 25(10): 17-31. https://doi.org/10.13653/j.cnki.jqte.2008.10.003

[33] Moran PA. (1948). The interpretation of statistical maps. Journal of the Royal Statistical Society B 10(2): 243 251. https://doi.org/10.2307/2332344

[34] Moran PA. (1950). Notes on continuous stochastic phenomena. Biometrika 37(1/2): 17-23. https://doi.org/10.2307/2332142

[35] Hettige H, Lucas REB, Wheeler D. (1992). The toxic intensity of industrial production; Global patterns, trends, and trade policy. American Economic Review 82(2): 478-481. https://www.jstor.org/stable/2117448

[36] Grossman GM, Krueger AB. (1991). Environmental impacts of the north American free trade agreement. National Bureau of Economics Research Working paper No. W3914.

[37] Yang R, Chang HY. (2012). Decoupling and driving factors analysis between the relationship of carbon emissions and economic growth in western region. Economic Geography 32(12): 478-481. https://doi.org/10.15957/j.cnki.jjdl.2012.12.006

[38] Ang BW. (1999). Is the energy intensity a less useful indicator than the carbon factor in the study of climate change. Energy Policy 27(15): 943-946. https://doi.org/10.1016/S0301-4215(99)00084-1

[39] Ezcurra R. (2007). Is There cross-country convergence in carbon dioxide emissions. Energy Policy 35(2): 13631372. https://doi.org/10.1016/j.enpol.2006.04.006

[40] Goulder LH, Schneider SH. (1999). Induced technological change and attractiveness of $\mathrm{CO} 2$ emissions abatement. Resource \& Energy Economics 21(3-4): 211-253. https://doi.org/10.1016/S09287655(99)00004-4

[41] Zhang H, Liu F, (2018). Spatial and temporal disparities in agricultural carbon emissions in xinjiang and decomposition of impact factors. Chemical Engineering Transactions 66: https://doi.org/10.3303/CET1866093 